\title{
Concentrated Bovine-Milk Whey Active Protein (CBP) Supplement- Combined Dynamic Flamingo Therapy (DFT) Activates Bone Metabolism and Bone-Related Factors
}

\section{Sangun Lee ${ }^{1 *}$, Junichi Hashimoto ${ }^{1}$, Takao Suzuki $^{1}$, Atsuko Satoh ${ }^{2}$, Barry Kavanagh $^{1}$, Takako Kumagai $^{3}$, Kiyonori Yamai ${ }^{4}$ and Shinji Ohta}

${ }^{1}$ Department of Physical Therapy, Aomori University of Health and Welfare, Aomori-shi, Japan

${ }^{2}$ Department of Nursing, Hirosaki University of Health and Welfare, Hirosaki-shi, Japan

${ }^{3}$ Department of Nutrition, Aomori University of Health and Welfare, Aomori-shi, Aomori, Japan

${ }^{4}$ Department of Gastroenterology and Hematology and Oncology, Odate Municipal General Hospital, Odata-shi, Japan

${ }^{5}$ Department of Obstetrics and Gynecology, Aomori Khosei Hospital, Aomori-shi, Japan

\begin{abstract}
Aims: In this study, we analyzed the effect of concentrated bovine-milk whey active protein (CBP) supplementcombined dynamic flamingo therapy (DFT) on bone metabolism and bone-related factors.

Methods: Subjects were menopausal women over 65 years of age, and they were divided into 3 groups C, DFT, and CBP-combined DFT (DFT-CBP) and analyzed for 2 months.

Results: The deoxypyridinoline (DPD) bone marker showed only a $27.7 \%$ decreased value in the DFT-CBP group after 2 months of treatment initiation, in comparison with the value before treatment $(p<0.01)$. However, the calcitonin was found with significant changes in all groups, but the DFT and DFT-CBP groups demonstrated a similar pattern of changes. The DFT-CBP group showed a $30.1 \%$ increased value after 1 month of treatment initiation, in comparison with the value before treatment, and a $37.1 \%$ decreased value after 2 months of treatment initiation $(p<0.001$, in each).
\end{abstract}

Discussion: This study demonstrated the synergistic effect of CBP supplement and an exercise load such as DFT. On the basis of these results, with the presence of a synergistic effect of a lightly loaded exercise and supplementation, bone improvement in menopausal women can be expected.

Keywords: Dynamic flamingo therapy; Bone metabolism mark; Body composition; Concentrated bovine-milk whey active protein supplement; Synergistic effect; Menopausal women

\section{Introduction}

Changes in internal secretions in menopausal women lead to bone loss and weakening of cross-linked structures [1,2]. Exercise and a nutritional intake are recommended for the prevention of bone loss and for bone improvement, which are influenced by a balance between bone formation and resorption. Previous studies have shown that bone mechanical stress associated with intense exercise is very important in bone improvement [3,4]. On the other hand, Appleby et al. [5], in a prospective study of women and the incidence of bone fracture, reported that exercise increased the relative risk of bone fracture. In contrast, dynamic flamingo therapy (DFT), which has been proposed as a safe and simple method, has been suggested to improve both the mechanical stress on the lower limbs and balancing ability [6-8]. However, the mechanism by which DFT leads to bone improvement is unclear, and its impact on bone metabolism remains undetermined.

In recent years, consumption of milk basic protein (MBP) supplement and similar dairy products has frequently been used in order to promote bone improvement [9-13]. Of these products, concentrated bovine-milk whey active protein (CBP) has been shown to induce bone formation in vitro, and has attracted interest as a method of bone improvement $[12,13]$. CBP directly affects bones by acting on osteoblasts [12] and indirectly by acting on growth hormone (GH) [13]. However, although the possibility that an intake of CBP alone leads to bone improvement in middle-aged men and women has been suggested, the specific mechanism underlying its role in bone metabolism and other bone-related factors has yet to be established [14]. Previous research on bones and nutritional intake has given rise to disagreement [15-17], with some reports claiming bone improvement and others showing no change [18-20]. Accordingly, at present, no consensus has been reached $[15,21]$. In contrast, bone improvement has been reported when nutritional intake is combined with exercise, in which the combined use of CBP supplement and DFT results in a safer, positive, and synergistic effect on bone improvement.

This study examined the impact of DFT combined with CBP supplement on bone metabolism and bone-related factors among menopausal women. The present study also aimed to clarify the manner in which the synergistic effect of DFT and CBP supplements causes changes in bone metabolism.

\section{Materials and Methods}

\section{Subjects}

Subjects were 35 menopausal women more than 65 years of age $(71.9 \pm 6.3 \mathrm{yr})$, who did not have any major illness or a history of illness

*Corresponding author: Sangun Lee, Ph.D, Department of Physical Therapy, Aomori University of Health and Welfare, 58-1 Hamadate Mase, Aomori, Aomori, 030-8505, Japan, Tel: +81-17-765-2000; Fax: +81-17-765-2000 E-mail: leesu@auhw.ac.jp

Received February 04, 2013; Accepted February 20, 2013; Published February 26, 2013

Citation: Lee S, Hashimoto J, Suzuki T, Satoh A, Kavanagh B, et al. (2013) Concentrated Bovine-Milk Whey Active Protein (CBP) Supplement-Combined Dynamic Flamingo Therapy (DFT) Activates Bone Metabolism and Bone-Related Factors. J Diabetes Metab 4: 251. doi:10.4172/2155-6156.1000251

Copyright: (c) 2013 Lee S, et al. This is an open-access article distributed unde the terms of the Creative Commons Attribution License, which permits unrestricted use, distribution, and reproduction in any medium, provided the original author and source are credited. 
Citation: Lee S, Hashimoto J, Suzuki T, Satoh A, Kavanagh B, et al. (2013) Concentrated Bovine-Milk Whey Active Protein (CBP) SupplementCombined Dynamic Flamingo Therapy (DFT) Activates Bone Metabolism and Bone-Related Factors. J Diabetes Metab 4: 251. doi:10.4172/2155-6156.1000251

Page 2 of 6

and were confirmed to have no problems for CBP supplementation. Subjects consisted of people who were below the healthy level of bone mass $(63.1 \pm 2.4 \%$, ratio for young adult mean) as stipulated by the Japanese Society for Bone and Mineral Research [22]. The subjects were assigned randomly to 3 groups: C, DFT, and DFT-CBP. The informed consent was obtained from all subjects, and this research has been approved by the department of ethics committee at the Aomori University of Health and Welfare (No.11022).

\section{Questionnaire}

A self-completion questionnaire was handed out to the subjects, and was collected on the day of blood sampling after individual interviews. The items asked in the questionnaire consisted of age, menarche, menopause, smoking, drinking, and exercise habits, status of major diseases, osteoporosis, fracture, and medication including the use of Non-steroidal anti-inflammatory drugs (NSAIDs).

\section{DFT protocol and CBP Supplement}

In terms of the DFT implementation method, the subjects were requested to stand on one leg with both hands on the sides (on each leg, right and left, for $1 \mathrm{~min}$ and 3 times a day [morning, noon, and night]) $[6,23]$. In addition, for safety, the subjects were allowed to grab the wall, desk, or handrail. A total count of $1 \mathrm{~min}$ was allowed even when the subject did not stand continuously for $1 \mathrm{~min}$. DFT was performed more than 5 times per week for 2 months. The DFT-CBP group was administered an oral CBP supplement (Seperex Nutritionals Ltd., New Zealand) of 1 tablet per day (CBP $60 \mathrm{mg} /$ Tablet) after breakfast for 2 months.

\section{Body composition and Bone Mineral Density (BMD)}

Anthropometric parameters measured the BW, the body mass index (BMI), the basal metabolic rate (BMR), the body fat percentage (\%fat), the lean body mass (LBM), the muscle mass, the bone mineral mass (BMM), the total body water, the intracellular fluid (ICF) and the extracellular fluid (ECF) with the body composition analyzer 'In Body 3.0' (Biospace Co., Japan) using the multifrequency $(5 \sim 500 \mathrm{kHz})$ bioimpedance method, after measuring height.

Bone mineral density was measured using the A1000 EXPRESS (General Electric Co, USA) ultrasound wave specifications and the side of the calcaneus which does not have an anamnesis injury was measured.

\section{Blood chemistry parameters}

Subjects were told to fast and their blood was collected from the antecubital vein in a sitting position, and blood composition was analyzed using the automatic blood cell counter 'SE-9000' (Sysmex Co., Japan). Serum samples were separated from blood samples by centrifugation for $10 \mathrm{~min}$ at $3000 \mathrm{rpm}$ and kept frozen at $-30^{\circ} \mathrm{C}$ until used for measurement at a later date. The measurement items of the serum elements included total cholesterol (TC) levels, HDL-cholesterol (HDL-C), triglyceride (TG), high density lipoprotein cholesterol (HDL-C) and low density lipoprotein cholesterol (LDL-C). The blood measured the TC, HDL-C, TG and LDL-C by enzyme methods.

\section{Maker of bone metabolism and hormones}

The markers of bone formation used through the 'UNICEL DXL 800' (Beckman Coulter, Inc., Japan) and measured bone specific alkaline phosphatase (BAP) the chemiluminescent enzyme immunoassay (CLEIA). The chemical reagent used the 'Access BAP kit' (Beckman Coulter, Inc., Japan). Meanwhile, the bone resorption marker used the 'fully automated microplate EIA analyzer AP-X' (Kyowa Medex Co., Ltd. Japan) and measured deoxypiridinoline (DPD) through the Enzyme Immunoassay (EIA) method. The chemical reagent used 'Osteolinks-DPD kit' (DS Pharma Biomedical Co., Ltd. Japan).

The Calcitonin (CT) hormone was measured using the '50 WELL GAMMA COUNTER ARC950' (Hitachi Aloka Medical, Ltd. Japan), and through the double antibody radioimmunoassay method. The chemical reagent used 'calcitonin RIA-Mitsubishi kit' (Mitsubishi Chemical Medience co. Japan). Meanwhile, the PTH-intact was measured by the chemiluminescent enzyme immunoassay (CLEIA) method using the 'UNICEL DXL 800' Beckman Coulter, Inc., Japan). The chemical reagent used 'Access intact PTH kit' (Beckman Coulter, Inc., Japan).

\section{Statistical analysis}

The results are shown as mean values and standard deviation (SD). Multiple comparisons in each group between before treatment and 1 month or 2 months after treatment initiation were performed using Tukey's HSD test. The analysis was performed using the IBM SPSS Statistics (Ver.19.0) and statistical significance was set at $p<0.05$.

\section{Results}

The physical characteristics and lifestyle of subjects are shown in table $1($ mean $\pm \mathrm{SD})$.

\section{Body composition}

There were no significant changes in the body composition in all groups (Table 2).

\section{Blood chemistry parameters}

There were no significant changes in the blood composition such as lipid related items, in all groups (Table 3).

\section{Maker of bone metabolism}

There were no significant changes in the BAP in all groups. However, the DPD bone marker showed only a $27.7 \%$ decreased value in the DFT-CBP group after 2 months of treatment initiation, in comparison with the value before treatment $(\mathrm{p}<0.01)$ (Figure 1).

\section{Hormones}

Compared to before treatment initiation, $30.6 \%$ of decreased calcitonin of $\mathrm{C}$ group was seen 2 months after treatment initiation. Further, compared to the value 1 month after treatment initiation, a $27.4 \%$ decreased value was observed after 2 months of treatment $(\mathrm{p}<0.05)$ (Figure 2).

\begin{tabular}{|c|c|c|}
\hline Height $\mathrm{cm}$ & & $149.5 \pm 5.43$ \\
\hline Body weight, $\mathrm{kg}$ & & $52.7 \pm 7.99$ \\
\hline Body mass index, $\mathrm{kg} / \mathrm{m}^{2}$ & & $23.5 \pm 3.22$ \\
\hline Basal metabolic rate, kcal & & $1067.5 \pm 71.25$ \\
\hline Menarche, yr & & $14.7 \pm 1.87$ \\
\hline Postmenopausal, yr & & $47.9 \pm 6.11$ \\
\hline \multirow{2}{*}{ Smoking habit ( $\leqq 1$ cigarettes/day), n (\%) } & Smokers & $2(5.7)$ \\
\hline & Non-smoker & $33(94.3)$ \\
\hline \multirow{2}{*}{ Alcohol habit ( $\leqq 1 \mathrm{mg}$ alcohol/week), $\mathrm{n}(\%)$} & Drinkers & $7(20.0)$ \\
\hline & Non-drinker & $28(80.0)$ \\
\hline \multirow{2}{*}{ Exercise ( $\leqq 1$ once/week), n (\%) } & Exercise & $10(28.6)$ \\
\hline & Non-exercise & $25(71.4)$ \\
\hline
\end{tabular}

Values are the mean \pm standard deviation

Table 1: Characteristics of subjects. 
Citation: Lee S, Hashimoto J, Suzuki T, Satoh A, Kavanagh B, et al. (2013) Concentrated Bovine-Milk Whey Active Protein (CBP) SupplementCombined Dynamic Flamingo Therapy (DFT) Activates Bone Metabolism and Bone-Related Factors. J Diabetes Metab 4: 251. doi:10.4172/2155-6156.1000251

Page 3 of 6

\begin{tabular}{|c|c|c|c|c|c|}
\hline & & Before & After 1 mount & After 2 mount & p-values \\
\hline \multirow{7}{*}{$\begin{array}{c}\text { Control } \\
(n=7)\end{array}$} & Body fat percentage, $\%$ & $33.4 \pm 3.32$ & $33.4 \pm 3.55$ & $33.4 \pm 2.48$ & 1.000 \\
\hline & Lean body mass, kg & $33.8 \pm 3.45$ & $34.0 \pm 3.64$ & $33.5 \pm 3.55$ & 0.963 \\
\hline & Muscle mass, kg & $31.8 \pm 3.31$ & $32.0 \pm 3.46$ & $31.5 \pm 3.42$ & 0.961 \\
\hline & Bone mass, $\mathrm{kg}$ & $2.0 \pm 0.15$ & $2.1 \pm 0.16$ & $2.0 \pm 0.16$ & 0.968 \\
\hline & Total body water, $\ell$ & $23.3 \pm 2.41$ & $23.5 \pm 2.53$ & $23.1 \pm 2.49$ & 0.964 \\
\hline & Intracellular fluid, $\ell$ & $15.3 \pm 1.71$ & $15.4 \pm 1.78$ & $15.1 \pm 1.78$ & 0.939 \\
\hline & Extracellular fluid, $\ell$ & $8.0 \pm 0.74$ & $8.0 \pm 0.78$ & $8.0 \pm 0.74$ & 0.998 \\
\hline \multirow{7}{*}{$\begin{array}{c}\text { DFT } \\
(n=14)\end{array}$} & Body fat percentage, $\%$ & $31.1 \pm 5.76$ & $30.5 \pm 5.79$ & $31.6 \pm 6.19$ & 0.909 \\
\hline & Lean body mass, kg & $35.9 \pm 4.94$ & $37.0 \pm 4.13$ & $36.9 \pm 5.30$ & 0.836 \\
\hline & Muscle mass, kg & $33.8 \pm 4.73$ & $34.8 \pm 3.95$ & $34.7 \pm 5.09$ & 0.844 \\
\hline & Bone mass, $\mathrm{kg}$ & $2.1 \pm 0.21$ & $2.2 \pm 0.18$ & $2.2 \pm 0.23$ & 0.838 \\
\hline & Total body water, $\ell$ & $24.8 \pm 3.46$ & $25.5 \pm 2.90$ & $25.4 \pm 3.73$ & 0.841 \\
\hline & Intracellular fluid, $\ell$ & $16.3 \pm 2.21$ & $16.8 \pm 1.95$ & $16.8 \pm 2.41$ & 0.826 \\
\hline & Extracellular fluid, $\ell$ & $8.4 \pm 1.28$ & $8.7 \pm 1.00$ & $8.6 \pm 1.34$ & 0.873 \\
\hline \multirow{7}{*}{$\begin{array}{c}\text { DFT -CBP } \\
(n=14)\end{array}$} & Body fat percentage, $\%$ & $30.1 \pm 6.28$ & $30.2 \pm 6.16$ & $31.5 \pm 5.93$ & 0.809 \\
\hline & Lean body mass, kg & $37.2 \pm 3.69$ & $37.1 \pm 3.83$ & $37.1 \pm 3.95$ & 0.992 \\
\hline & Muscle mass, kg & $35.0 \pm 3.54$ & $34.9 \pm 3.65$ & $34.9 \pm 3.77$ & 0.993 \\
\hline & Bone mass, $\mathrm{kg}$ & $2.2 \pm 0.16$ & $2.2 \pm 0.17$ & $2.2 \pm 0.17$ & 0.990 \\
\hline & Total body water, $\ell$ & $25.7 \pm 2.59$ & $25.6 \pm 2.67$ & $25.5 \pm 2.78$ & 0.988 \\
\hline & Intracellular fluid, $\ell$ & $16.9 \pm 1.73$ & $17.0 \pm 1.79$ & $17.0 \pm 1.86$ & 0.989 \\
\hline & Extracellular fluid, $\ell$ & $8.8 \pm 0.87$ & $8.6 \pm 0.90$ & $8.6 \pm 0.94$ & 0.831 \\
\hline
\end{tabular}

Values are the mean \pm standard deviation

DFT: Dynamic Flamingo Therapy; CBP: Concentrated Bovine-Milk Whey Active Protein

Table 2: The comparison of the body compositions production between the 2 months (ANOVA).

\begin{tabular}{|c|c|c|c|c|c|}
\hline & & Before & After 1 mount & After 2 mount & $p$-values \\
\hline \multirow{7}{*}{$\begin{array}{l}\text { Control } \\
(n=7)\end{array}$} & Leukocyte, / $\mu \ell$ & $5258.6 \pm 967.0$ & $5890.0 \pm 851.3$ & $5598.0 \pm 675.1$ & 0.390 \\
\hline & Erythrocyte, / $\mu \ell\left(10^{4}\right)$ & $448.1 \pm 28.3$ & $445.4 \pm 35.1$ & $448.4 \pm 35.7$ & 0.983 \\
\hline & Calcium, mg / d $\ell$ & $9.1 \pm 0.24$ & $9.4 \pm 0.39$ & $8.9 \pm 0.37$ & 0.046 \\
\hline & $\mathrm{TC}, \mathrm{mg} / \mathrm{d} \ell$ & $208.1 \pm 16.17$ & $218.7 \pm 15.04$ & $212.0 \pm 21.13$ & 0.537 \\
\hline & $\mathrm{TG}, \mathrm{mg} / \mathrm{d} \ell$ & $127.7 \pm 79.69$ & $92.0 \pm 37.29$ & $106.1 \pm 31.26$ & 0.474 \\
\hline & $\mathrm{HDL}-\mathrm{C}, \mathrm{mg} / \mathrm{d} \ell$ & $62.6 \pm 9.61$ & $68.0 \pm 8.76$ & $67.0 \pm 11.69$ & 0.573 \\
\hline & LDL-C, mg / d $\ell$ & $113.1 \pm 29.66$ & $131.0 \pm 24.34$ & $118.4 \pm 25.22$ & 0.449 \\
\hline \multirow{7}{*}{$\begin{array}{c}\text { DFT } \\
(n=14)\end{array}$} & Leukocyte, / $\mu \ell$ & $4956.4 \pm 1317.7$ & $4964.4 \pm 1418.1$ & $4626.0 \pm 1511.5$ & 0.823 \\
\hline & Erythrocyte, / $\mu \ell\left(10^{4}\right)$ & $428.4 \pm 34.63$ & $424.6 \pm 39.27$ & $430.5 \pm 36.39$ & 0.937 \\
\hline & Calcium, mg / d $\ell$ & $9.0 \pm 0.36$ & $8.9 \pm 0.40$ & $9.1 \pm 0.41$ & 0.405 \\
\hline & $\mathrm{TC}, \mathrm{mg} / \mathrm{d} \ell$ & $181.4 \pm 32.29$ & $176.8 \pm 19.18$ & $179.4 \pm 22.06$ & 0.918 \\
\hline & $\mathrm{TG}, \mathrm{mg} / \mathrm{d} \ell$ & $98.5 \pm 41.86$ & $82.4 \pm 38.21$ & $95.8 \pm 45.66$ & 0.659 \\
\hline & $\mathrm{HDL}-\mathrm{C}, \mathrm{mg} / \mathrm{d} \ell$ & $51.6 \pm 15.37$ & $60.8 \pm 14.99$ & $58.2 \pm 15.08$ & 0.332 \\
\hline & LDL-C, mg / d $\ell$ & $96.6 \pm 23.88$ & $84.7 \pm 18.55$ & $90.2 \pm 26.75$ & 0.495 \\
\hline \multirow{7}{*}{$\begin{array}{c}\text { DFT -CBP } \\
\quad(n=14)\end{array}$} & Leukocyte, / $\mu \ell$ & $5105.7 \pm 991.4$ & $5162.5 \pm 1196.0$ & $4769.1 \pm 1245.8$ & 0.673 \\
\hline & Erythrocyte, / $\mu \ell\left(10^{4}\right)$ & $424.3 \pm 28.26$ & $428.2 \pm 26.62$ & $432.3 \pm 31.65$ & 0.790 \\
\hline & Calcium, mg / d $\ell$ & $9.1 \pm 0.36$ & $9.0 \pm 0.30$ & $9.1 \pm 0.30$ & 0.635 \\
\hline & $\mathrm{TC}, \mathrm{mg} / \mathrm{d} \ell$ & $194.0 \pm 32.01$ & $200.3 \pm 27.72$ & $197.7 \pm 36.35$ & 0.880 \\
\hline & $\mathrm{TG}, \mathrm{mg} / \mathrm{d} \ell$ & $109.0 \pm 36.55$ & $89.2 \pm 39.81$ & $107.4 \pm 32.46$ & 0.339 \\
\hline & $\mathrm{HDL}-\mathrm{C}, \mathrm{mg} / \mathrm{d} \ell$ & $55.1 \pm 12.53$ & $60.7 \pm 15.55$ & $56.6 \pm 10.68$ & 0.555 \\
\hline & LDL-C, $\mathrm{mg} / \mathrm{d} \ell$ & $106.1 \pm 29.41$ & $109.3 \pm 26.64$ & $110.7 \pm 33.14$ & 0.924 \\
\hline
\end{tabular}

Values are the mean \pm standard deviation

DFT: Dynamic Flamingo Therapy; CBP: Concentrated Bovine-Milk Whey Active Protein; TC: Total Cholesterol; TG: Triglyceride; HDL-C: High Density LipoproteinCholesterol; LDL-C: Low Density Lipoprotein-Cholesterol

Table 3: The comparison of the blood elements production between the 2 months (ANOVA).

In the DFT group, a $29.1 \%$ increased value was observed after 1 month of treatment initiation, and a $35.3 \%$ decreased value was observed 2 months after treatment initiation. Further, a $49.8 \%$ decreased value was observed after 2 months of treatment, in comparison with the value after 1 month of treatment initiation $(\mathrm{p}<0.001)$ (Figure 2).

In the DFT-CBP group, a $30.1 \%$ increased value was observed after 1 month of treatment initiation, and a $37.1 \%$ decreased value after 2 months of treatment initiation. Further, a $51.7 \%$ decreased value was observed after 2 months of treatment, in comparison with the value after 1 month of treatment initiation $(\mathrm{p}<0.001)$. However, PTH-intact did not show any significant changes in either group (Figure 2).

\section{Discussion}

In this study, we analyzed the effect of CBP supplement-combined DFT on bone metabolism and bone-related factors among menopausal women. The results showed a significant inhibition of DPD in the DFT- 
Citation: Lee S, Hashimoto J, Suzuki T, Satoh A, Kavanagh B, et al. (2013) Concentrated Bovine-Milk Whey Active Protein (CBP) SupplementCombined Dynamic Flamingo Therapy (DFT) Activates Bone Metabolism and Bone-Related Factors. J Diabetes Metab 4: 251. doi:10.4172/2155-6156.1000251

Page 4 of 6
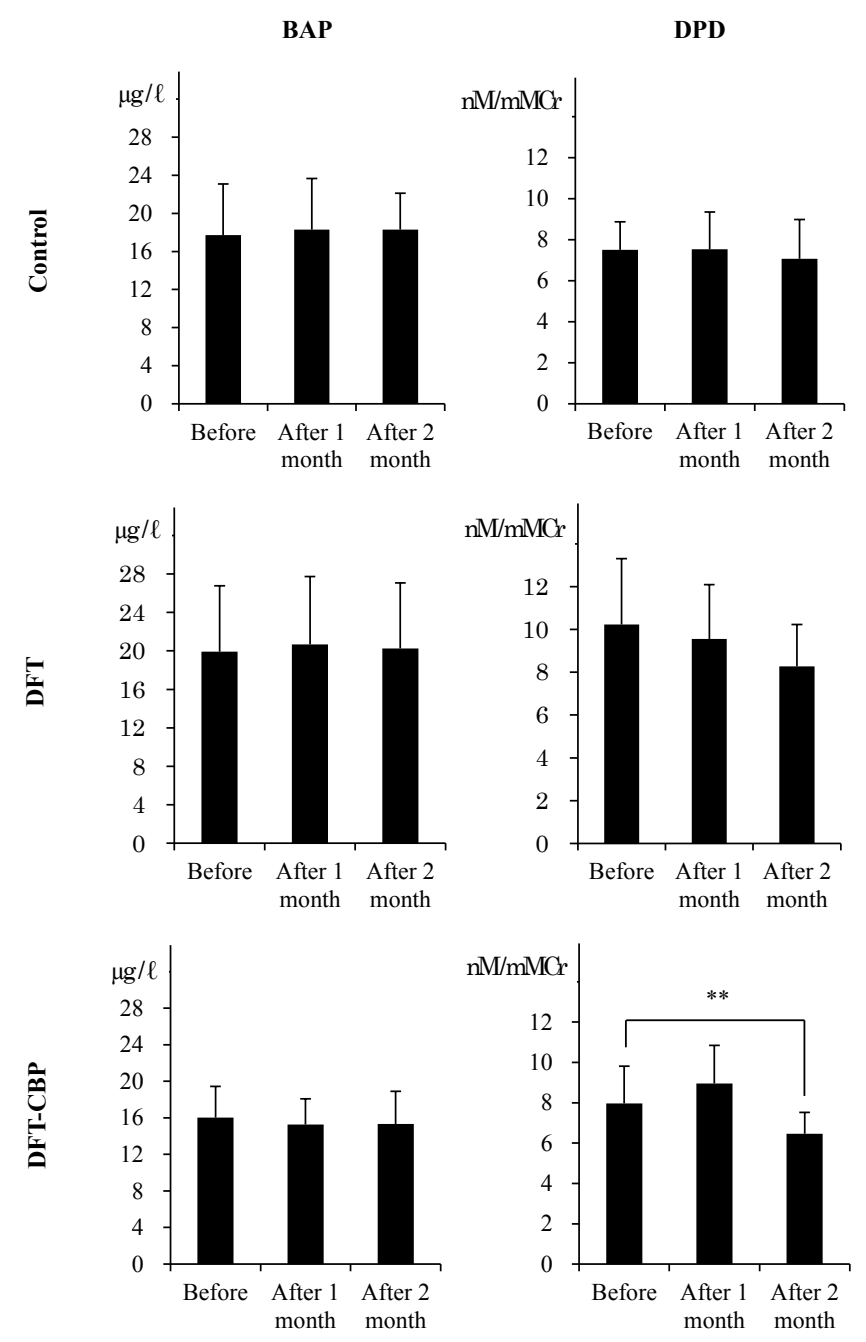

**: $p<0.01$, DFT: Dynamic Flamingo Therapy; CBP: Concentrated BovineMilk Whey Active Protein; BAP: Bone Alkaline Phosphatase; DPD: Deoxypyridinoline

Only the DFT-CBP and DPD groups demonstrated $18.9 \%$ of reduced bone metabolism after 2 months of treatment $(p<0.01)$

Figure 1: Changes in bone metabolism markers in each group within 2 months.

CBP group after 2 months of supplementation, as compared to baseline levels. The results also suggest a synergistic effect of CBP supplements with the CT-related properties of DFT.

$\mathrm{GH}$, which affects bones, was affected by whey protein and CBP $[12,13,24]$. GH is activated by increases in skeletal muscle mass and exercise intensity and is involved in lipid metabolism [25-28]. CBP, which is strongly related to $\mathrm{GH}$, has been reported to act directly and indirectly on bones $[12,13]$. Further, mechanical stress is essential for bone improvement [2], in which the act of standing on one leg for 1 minute gives the proximal part of the femur a load equivalent to that of 53 minutes of walking $[6,29,30]$. However, earlier research involving healthy middle-aged men and women fed with CBP alone has shown that this regimen by itself may directly result in bone improvement [14]. Moreover, DFT research by Sakamoto [6] showed a trend toward a partial increase in bone density, although this study did not show any significant improvement in bone health. Our results also showed no bone-related change in body composition or blood component. During the 2-month monitoring period, the required threshold for a change in body composition or blood component was not reached, and the combined effects of DFT and CBP on bone features were limited.

Fujimura et al. [31], using resistance exercise, and Woitge et al. [32], using aerobic exercise, reported a continuous decrease in DPD, although after a period of time, the subjects reverted back to their baseline values. In other words, DPD exhibits a biological reaction regardless of the type of exercise, and the difference in the regression time is influenced by the intensity of the exercise. Aoe et al. reported that a 6-month intake of MBP supplements resulted in a reduction in type I collagen cross-linked N-telopeptides (NTx) and suggested that bone improvement was suppressed by bone-resorbing factors $[9,10]$. Research by Zou et al. [11] also showed a reduction in NTx, despite a constant BAP, after MBP supplementation for 8 months. Furthermore, Rudman et al. [25] have shown that the administration of GH to elderly
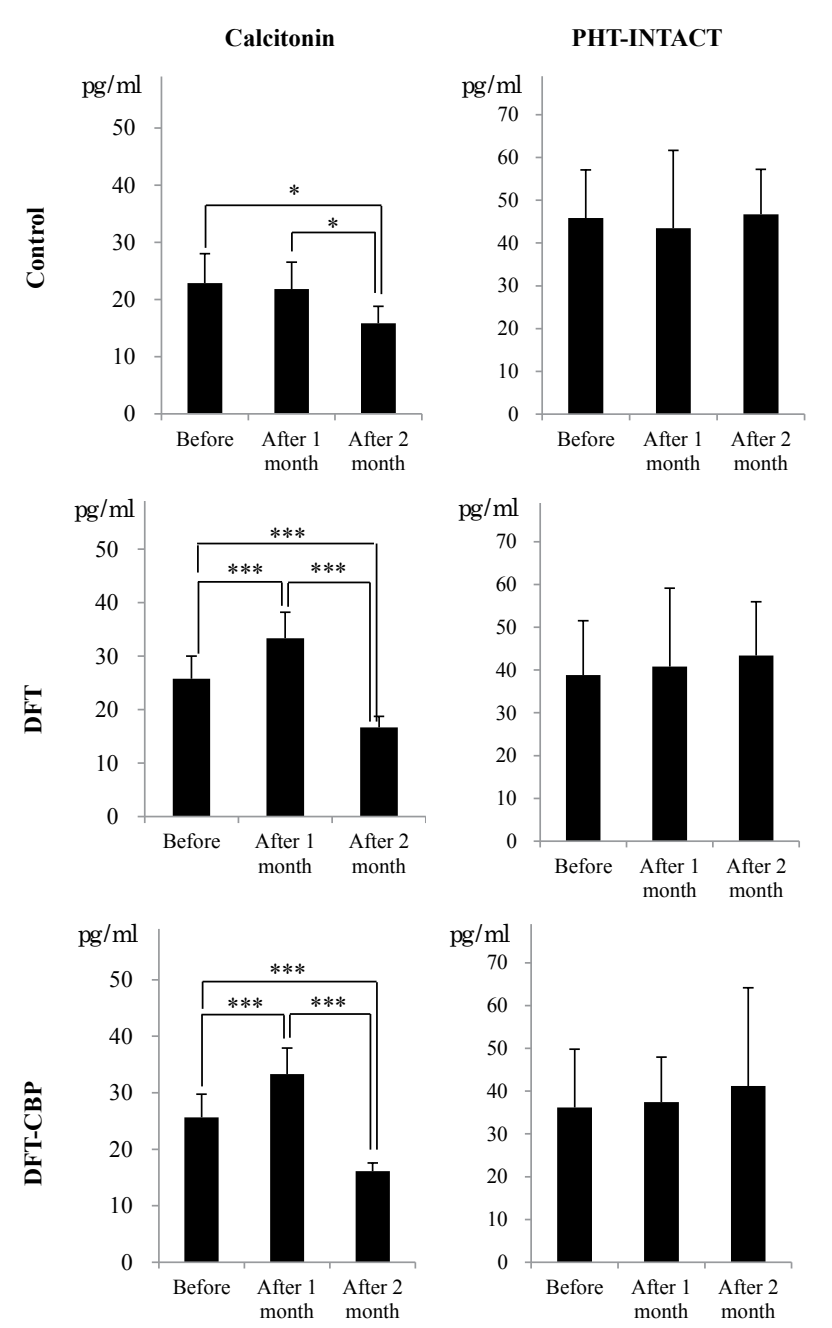

$*: p<0.05,{ }^{* * *}: p<0.001$, DFT: Dynamic Flamingo Therapy; CBP: Concentrated Bovine-Milk Whey Active Protein; BAP: Bone Alkaline Phosphatase; DPD: Deoxypyridinoline

Calcitonin levels in the $\mathrm{C}$ group were lower after both 1 and 2 months of treatment initiation $(p<0.05$, in each).In the DFT and DFT-CBP groups, increased values were observed after 1 month of treatment initiation, followed by a decrease after 2 months of treatment ( $p<0.001$, in each)

Figure 2: Changes in bone-related factors in each group within 2 months. 
Citation: Lee S, Hashimoto J, Suzuki T, Satoh A, Kavanagh B, et al. (2013) Concentrated Bovine-Milk Whey Active Protein (CBP) SupplementCombined Dynamic Flamingo Therapy (DFT) Activates Bone Metabolism and Bone-Related Factors. J Diabetes Metab 4: 251. doi:10.4172/2155-6156.1000251

Page 5 of 6

patients resulted in the activation of bone formation and resorption, with bone resorption predominating during initial bone remodeling.

On the basis of these results, it is suggested that bone resorption factors are readily affected by exercise and supplements and may play a central role in bone metabolism. The results of the present study show that the synergistic effect of CBP supplements and exercise may activate bone metabolism and resorption. On the other hand, although all groups showed a significant change in CT, no change in PHT, which is involved in CT reactions [33], was reported, thus suggesting the requirement for DFT implementation. In particular, changes in CT and DPD in the DFT-CBP group indicated an association. CT levels in the blood were altered neither by a short period of intense exercise nor by a long period of moderate exercise [34]. Given the amount of load and age of the subjects in the present study, it seems clinically unlikely that the changes would be associated with an increase in estrogen or other bone-related secretions. As such, CT readily reacts to weak loads, similar to the responses to routine daily activities or DFT. Further, CBP, which acts directly on osteoblasts, appeared to have little impact on CT.

In bone remodeling, inhibition is caused by a variety of bonerelated factors and interactions between cells [35,36]. Rodondi et al. [37] have reported that the combination of whey protein and other related factors imparts a synergistic effect on frail elderly patients. Given these facts, we feel that light, short-term exercise loading also prompts a synergistic effect with CBP supplement and may lead to a method for bone improvement.

In Japan, a safe and simple method for bone improvement for the elderly has yet to be established, prompting the need to identify effective approaches from the area of evidence-based medicine. The present study could not clarify the specific mechanism of coupling or the synergistic effect on bone-related factors. However, DFT with concomitant CBP supplement show the possibility of further enhancing the effects on bone and has potential as a method of bone improvement that is effective and safe.

As suggested in this short-term study, the changes in bone-related factors caused by DFT and CBP supplement over a long period will have to be studied. Further, investigation of the clinical effects of DFT and CBP supplement on patients with bone-related diseases should be continued, together with the efforts to understand the mechanism by which supplements affect the bone.

\section{Acknowledgements}

I gratefully appreciate the financial support of Grant-in-Aid from Aomori University of Health and Welfare that made it possible to complete my thesis. Finally, I would like to express my deepest gratitude to the nurses of the Nakasato health center whose enormous support and insightful comments were invaluable during the course of my study.

\section{References}

1. Rachner TD, Khosla S, Hofbauer LC (2011) Osteoporosis: now and the future Lancet 377: 1276-1287.

2. Zebaze RM, Ghasem-Zadeh A, Bohte A, luliano-Burns S, Mirams M, et al. (2010) Intracortical remodelling and porosity in the distal radius and postmortem femurs of women: a cross-sectional study. Lancet 375: 1729-1736.

3. Kontulainen S, Heinonen A, Kannus P, Pasanen M, Sievänen H, et al. (2004) Former exercisers of an 18-month intervention display residual a BMD benefits compared with control women 3.5 years post-intervention: a follow-up of a randomized controlled high-impact trial. Osteoporos Int 15: 248-251.

4. Vincent KR, Braith RW (2002) Resistance exercise and bone turnover in elderly men and women. Med Sci Sports Exerc 34: 17-23.

5. Appleby PN, Allen NE, Roddam AW, Key TJ (2008) Physical activity and fracture risk: a prospective study of 1898 incident fractures among 34,696 British men and women. J Bone Miner Metab 26: 191-198.

6. Sakamoto K (2008) [Dynamic flamingo therapy]. Clin Calcium 18: 1594-1599.

7. Iwamoto J, Otaka Y, Kudo K, Takeda T, Uzawa M, et al. (2004) Efficacy of training program for ambulatory competence in elderly women. Keio $\mathrm{J}$ Med 53: $85-89$

8. Sakamoto K, Nakamura T, Hagino H, Endo N, Mori S, et al. (2006) Committee on Osteoporosis of The Japanese Orthopaedic Association. Effects of unipedal standing balance exercise on the prevention of falls and hip fracture among clinically defined high-risk elderly individuals: a randomized controlled trial. $J$ Orthop Sci 11: 467-472.

9. Aoe S, Toba Y, Yamamura J, Kawakami H, Yahiro M, et al. (2001) Controlled trial of the effects of milk basic protein (MBP) supplementation on bone metabolism in healthy adult women. Biosci Biotechnol Biochem 65: 913-918.

10. Aoe S, Koyama T, Toba Y, Itabashi A, Takada Y (2005) A controlled trial of the effect of milk basic protein (MBP) supplementation on bone metabolism in healthy menopausal women. Osteoporos Int 16: 2123-2128.

11. Zou ZY, Lin XM, Xu XR, Xu R, Ma L, et al. (2009) Evaluation of milk basic protein supplementation on bone density and bone metabolism in Chinese young women. Eur J Nutr 48: 301-306.

12. Lee J, Kwon SH, Kim HM, Fahey SN, Knighton DR, et al. (2008) Effect of a Growth Protein-Colostrum Fraction on bone development in juvenile rats. Biosci Biotechnol Biochem 72: 1-6.

13. Jeongrai L, Hyun-Mi K, Hsseun C, Jeong-Hwa H (2007) Effects of Colostrum Basic Protein from Colostrum Whey Protein: Increases in Osteoblas Proliferation and Bone Metabolism. Journal of Food Science and Nutrition 12 1-6.

14. Kentarou N, Matsuta K (2009) Concentrated-bovine protein (CBP) increases bone mineral density. Japanese Journal of Integrative Medicine 2: 114-117.

15. Owecki M, Horst-Sikorska W, Baszko-Blaszyk D, Sowinski J (2002) [Influence of diet and physical activity on the course and therapy of osteoporosis]. Pol Merkur Lekarski 13: 473-476.

16. Riggs BL, O'Fallon WM, Muhs J, O'Connor MK, Kumar R, et al. (1998) Longterm effects of calcium supplementation on serum parathyroid hormone level, bone turnover, and bone loss in elderly women. J Bone Miner Res 13: 168-174.

17. Recker RR, Hinders S, Davies KM, Heaney RP, Stegman MR, et al. (1996) Correcting calcium nutritional deficiency prevents spine fractures in elderly women. J Bone Miner Res 11: 1961-1966.

18. Grant AM, Avenell A, Campbell MK, McDonald AM, MacLennan GS, et al. (2005) Oral vitamin D3 and calcium for secondary prevention of low-trauma fractures in elderly people (Randomised Evaluation of Calcium Or vitamin D RECORD): a randomised placebo-controlled trial. Lancet 365: 1621-1628.

19. Porthouse J, Cockayne S, King C, Saxon L, Steele E, et al. (2005) Randomised controlled trial of calcium and supplementation with cholecalciferol (vitamin D3) for prevention of fractures in primary care. BMJ 330: 1003.

20. Winzenberg TM, Shaw K, Fryer J, Jones G (2006) Calcium supplementation for improving bone mineral density in children. Cochrane Database Sys Rev 19: CD005119

21. Prince RL, Smith M, Dick IM, Price RI, Webb PG, et al. (1991) Prevention of postmenopausal osteoporosis. A comparative study of exercise, calcium supplementation, and hormone-replacement therapy. N Engl J Med 325: 1189 1195.

22. Nawata H, Soen S, Takayanagi R, Tanaka I, Subcommittee to Study Diagnostic Criteria for Glucocorticoid-Induced Osteoporosis, et al. (2005) Guidelines on the management and treatment of glucocorticoid-induced osteoporosis of the Japanese Society for Bone and Mineral Research (2004). J Bone Miner Metab 23. $105-109$.

23. Sakai A, Oshige T, Zenke $Y$, Yamanaka $Y$, Nagaishi H, et al. (2010) Unipeda standing exercise and hip bone mineral density in postmenopausal women: a randomized controlled trial. J Bone Miner Metab 28: 42-48.

24. Chevalley T, Hoffmeyer P, Bonjour JP, Rizzoli R (2010) Early serum IGFresponse to oral protein supplements in elderly women with a recent hip fracture. Clin Nutr 29: 78-83.

25. Rudman D, Feller AG, Nagraj HS, Gergans GA, Lalitha PY, et al. (1990) Effects of human growth hormone in men over 60 years old. N Engl J Med 323: 1-6. 
Citation: Lee S, Hashimoto J, Suzuki T, Satoh A, Kavanagh B, et al. (2013) Concentrated Bovine-Milk Whey Active Protein (CBP) SupplementCombined Dynamic Flamingo Therapy (DFT) Activates Bone Metabolism and Bone-Related Factors. J Diabetes Metab 4: 251. doi:10.4172/2155-6156.1000251

Page 6 of 6

26. Sotiropoulos A, Ohanna M, Kedzia C, Menon RK, Kopchick JJ, et al. (2006) Growth hormone promotes skeletal muscle cell fusion independent of insulinlike growth factor 1 up-regulation. Proc Natl Acad Sci U S A 103: 7315-7320.

27. Goto K, Choi J, Ohyama BK, Takamatsu K (2003) Differences in characteristic between Strength-up type and Bulk-up type of resistance exercise: with reference to EMG activity and growth hormone secretion. Japanese Society of Physical Education 48: 383-393.

28. Abdul Shakoor SK, Shalet SM (2003) Effects of GH replacement on metabolism and physical performance in $\mathrm{GH}$ deficient adults. J Endocrinol Invest 26: 911918

29. Takashi N, Keizo S, Hideyo M (2008) Fall-down fracture incident mechanism and its prevention by one-leg standing exercise. Journal of the Eastern Japan Association of Orthopaedics and Traumatology 20: 119-124.

30. Tashiro Y, Sakamoto K (2003) The study for effects of single-standing on the prevention of femoral neck fracture. Journal of Japanese Society of Bone Morphometry 13: 21-26.

31. Fujimura R, Ashizawa N, Watanabe M, Mukai N, Amagai H, et al. (1997) Effect of resistance exercise training on bone formation and resorption in young male subjects assessed by biomarkers of bone metabolism. J Bone Miner Res 12 : 656-662.

32. Woitge HW, Friedmann B, Suttner S, Farahmand I, Müller M, et al. (1998) Changes in bone turnover induced by aerobic and anaerobic exercise in young males. J Bone Miner Res 13: 1797-1804.

33. Henley C 3rd, Yang Y, Davis J, Lu JY, Morony S, et al. (2011) Discovery of a calcimimetic with differential effects on parathyroid hormone and calcitonin secretion. J Pharmacol Exp Ther 337: 681-691.

34. Nishiyama S, Tomoeda S, Ohta T, Higuchi A, Matsuda I (1988) Differences in basal and postexercise osteocalcin levels in athletic and nonathletic humans. Calcif Tissue Int 43: 150-154

35. Hayden JM, Mohan S, Baylink DJ (1995) The insulin-like growth factor system and the coupling of formation to resorption. Bone 17: 93S-98S.

36. Matsuo K, Irie N (2008) Osteoclast-osteoblast communication. Arch Biochem Biophys 473: 201-209

37. Rodondi A, Ammann P, Ghilardi-Beuret S, Rizzoli R (2009) Zinc increases the effects of essential amino acids-whey protein supplements in frail elderly. $J$ Nutr Health Aging 13: 491-497. 